\title{
Bilateral Variation of Lateral Root of Median Nerve traversing through Coracobrachialis Muscle
}

\author{
${ }^{1}$ Anjali Aggarwal, ${ }^{2}$ Tulika Gupta, ${ }^{3}$ Aditya Aggarwal, ${ }^{4}$ Daisy Sahni
}

\begin{abstract}
An unusual bilateral variation of lateral root of median nerve piercing through coracobrachialis muscle is presented. Two nerve filaments to coracobrachialis muscle took unusual origin from medial cord, which crossed the axillary artery from medial to lateral side before entering the muscle. Variation of lateral root of median nerve may be clinically significant, as hitherto unreported entrapment neuropathy of median nerve along with musculocutaneous may occur at the arm level while passing through coracobrachialis muscle or it may be injured during any surgical intervention around shoulder joint. Nerves to coracobrachialis are at risk during unusual abduction of arm or surgical manipulation of axillary artery.
\end{abstract}

Keywords: Coracobrachialis, Lateral root of median nerve, Musculocutaneous nerve.

How to cite this article: Aggarwal A, Gupta T, Aggarwal A, Sahni D. Bilateral Variation of Lateral Root of Median Nerve traversing through Coracobrachialis Muscle. J Postgrad Med Edu Res 2016;50(3):159-161.

Source of support: Nil

Conflict of interest: None

\section{INTRODUCTION}

The nerves entering coracobrachialis muscle are usually musculocutaneous nerve and thin branches to coracobrachialis. ${ }^{1}$ These nerves are susceptible to injury during any surgical procedure involving coracoid process transfer or management of fracture dislocation of clavicle. ${ }^{2,3}$ Strenuous exercises, such as weight lifting or push-ups have been found to be associated with compression of musculocutaneous nerve because of its passage through coracobrachialis muscle. ${ }^{4}$

\section{CASE REPORT}

During practical teaching for undergraduate students, on a 48-year-old embalmed male cadaver's upper

\footnotetext{
${ }^{1,2}$ Assistant Professor, ${ }^{3}$ Additional Professor, ${ }^{4}$ Professor

${ }^{1,2,4}$ Department of Anatomy, Postgraduate Institute of Medical Education and Research, Chandigarh, India

${ }^{3}$ Department of Orthopaedic Surgery, Postgraduate Institute of Medical Education and Research, Chandigarh, India

Corresponding Author: Anjali Aggarwal, Assistant Professor Department of Anatomy, Postgraduate Institute of Medical Education and Research, Chandigarh, India, Phone: +911722727726, e-mail: anjli_doc@yahoo.com;anjali.agg09@ gmail.com
}

extremity, an aberrant course of lateral root of median nerve (LRMN) was noticed. For descriptive purpose, most inferior point of tip of coracoid process and tip of medial epicondyle were considered as reference points. All necessary measurements were taken with a precision caliper (Mitutoyo, Kawasaki Kanagana, Japan). Both arms were $30 \mathrm{~cm}$ in length.

\section{Aberrant Course of Lateral Root of Median Nerve}

On the right side (Fig. 1), lateral cord terminally bifurcated into musculocutaneous nerve and LRMN at the level of coracoid process. Lateral root of median nerve accompanied musculocutaneous nerve and both nerves coursed through the coracobrachialis muscle. Musculocutaneous and LRMN entered the medial surface of coracobrachialis 44.3 and $48.9 \mathrm{~mm}$ distal to coracoid process respectively. Lateral root after a short oblique intramuscular course emerged out of the muscle $88 \mathrm{~mm}$ distal to coracoid process and joined with medial root of median nerve $116.3 \mathrm{~mm}$ distal to coracoid process. Both lateral root and musculocutaneous nerves passed through the same plane and divided coracobrachialis into superficial and deep parts. Similarly on the left side, LRMN accompanied musculocutaneous nerve to pass through the coracobrachialis 55.6 and $51.5 \mathrm{~mm}$ distal to coracoid process respectively and emerged out of it

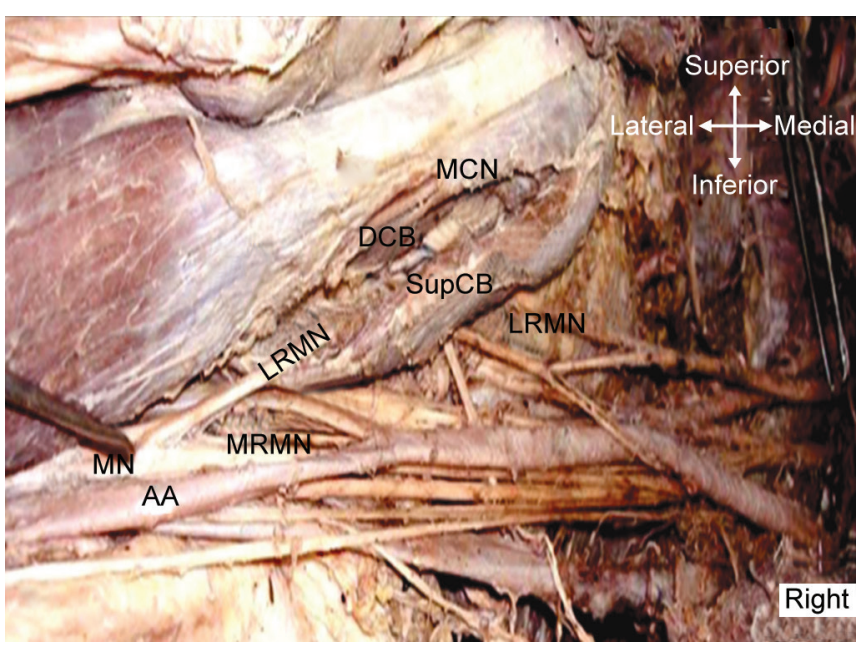

Fig. 1: Anomalous course of LRMN through coracobrachialis on the right side; MCN: Musculocutaneous nerve; LRMN: Lateral root of median nerve; AA: Axillary artery; MRMN: Medial root of median nerve; MN: Median nerve; SupCB: Part of coracobrachialis superficial to MCN and LRMN; DCB: Part of coracobrachialis deep to MCN and LRMN 


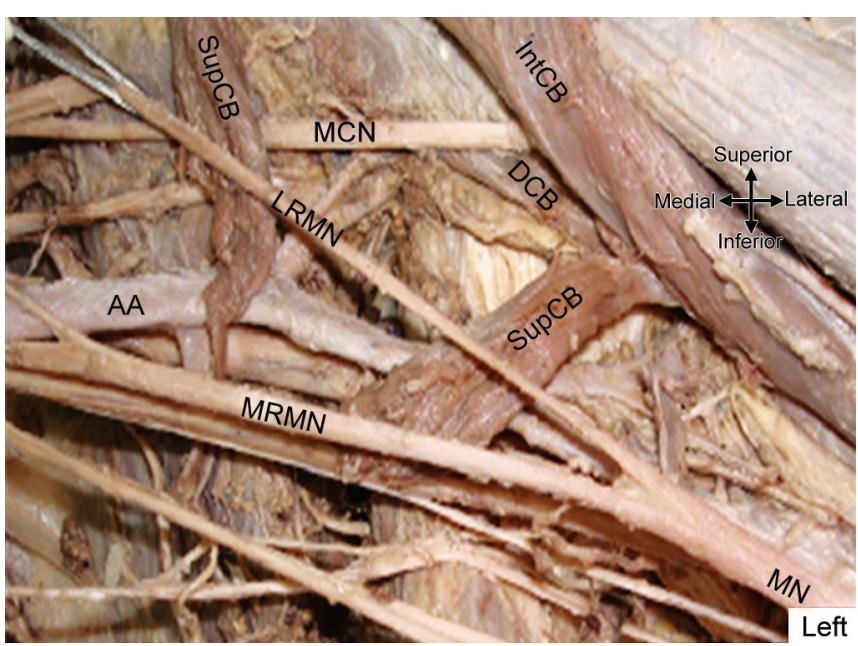

Fig. 2A: Course of musculocutaneous nerve and LRMN traversing through different planes (after cutting coracobrachialis superficial to lateral root) on the left side; SupCB: Coracobrachialis superficial to LRMN; IntCB: Intermediate part of coracobrachialis between lateral root and musculocutaneous nerve; DCB: Coracobrachialis deep to musculocutaneous nerve. For rest of abbreviations consult Figure 1

$74.1 \mathrm{~mm}$ inferior to coracoid process (Fig. 2A). Lateral root of median nerve joined the medial root of median nerve $109.7 \mathrm{~mm}$ distal to coracoid process to form the median nerve. Both nerves traversed through different planes of muscle and divided the later into three strata: Superficial stratum - superficial to lateral root, intermediate stratum between LRMN and musculocutaneous nerve, and deep stratum - deep to musculocutaneous nerve. During passage through the muscle no communication between two nerves was found. Fusion of two roots of median nerve was much inferior to usual level of fusion. Length of lateral root before piercing coracobrachialis muscle was $62 \mathrm{~mm}$ on the right and $61.4 \mathrm{~mm}$ on the left side whereas that of musculocutaneous nerve was $58.9 \mathrm{~mm}$ on the right and $64 \mathrm{~mm}$ on the left side. Both nerves entered coracobrachialis muscle in its lower third.

\section{Nerves to Coracobrachialis}

On the left side, three nerve filaments to coracobrachialis muscle were observed. Two arose from musculocutaneous nerve and one from lateral cord, which entered the muscle 26.0, 30.4, and $32.0 \mathrm{~mm}$ distal to coracoid process respectively (Fig. 2B). Similarly on the right side, three nerve filaments were found, one from musculocutaneous nerve and two from medial cord. These nerve filaments entered the coracobrachialis 32.4, 40.0, and $60.6 \mathrm{~mm}$ distal to coracoid process respectively.

\section{DISCUSSION}

Median nerve is most frequently formed by two roots: Single lateral root from the lateral cord and single medial

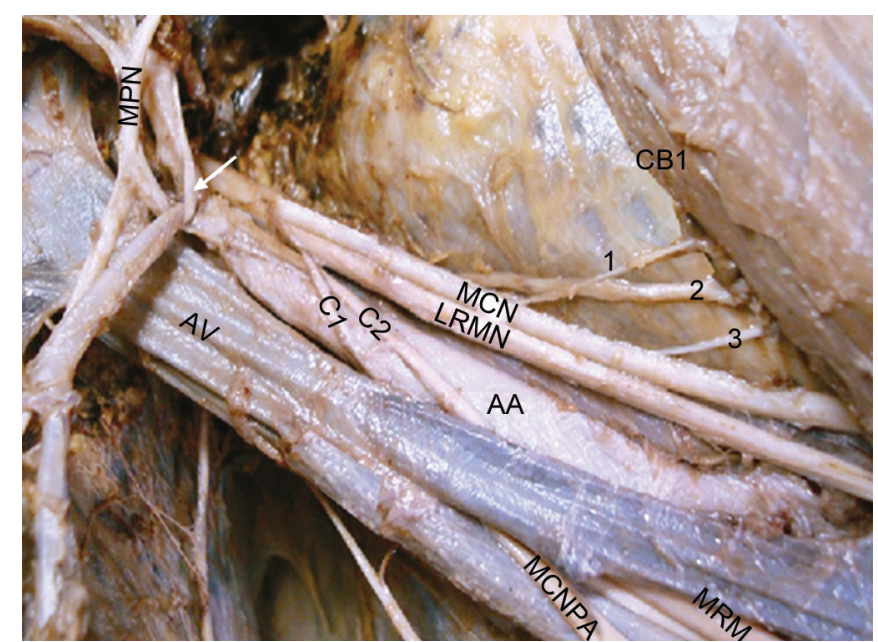

Fig. 2B: Multiple branches to coracobrachialis on left side before removing axillary vein; two from musculocutaneous nerve and one from LRMN; AV: Axillary vein; MPN: Medial pectoral nerve; MCNFA: Medial cutaneous nerve of forearm

root from the medial cord, which unite anterior or lateral to the axillary artery. ${ }^{1}$ Abhaya et $\mathrm{al}^{5}$ and Butz et $\mathrm{al}^{6}$ reported cases of lateral cord of median nerve piercing the coracobrachialis muscle before its bifurcation into musculocutaneous and LRMN. However, they did not describe the course of two terminal branches of lateral cord within the muscle. In our case, the lateral cord terminally bifurcated into musculocutaneous and LRMN and both branches pierced the coracobrachialis muscle which is a rare feature. On the left side, these two nerves passed through the muscle in different planes, thus dividing the muscle into three parts: Superficial, intermediate, and deep parts. On the right side, both nerves traversed the muscle in the same plane, dividing the muscle into superficial and deep parts only. According to hypothesis given by Sannes et al, ${ }^{7}$ chemoattractants and chemorepulsants regulate in a highly coordinated site-specific fashion the fate of the developing axons. Any alterations in signaling between mesenchymal cells and neuronal growth cones or circulatory factors at the time of fusion of brachial plexus can lead to significant variations. This might have probably contributed or caused this rare variation of coracobrachialis muscle being pierced by LRMN bilaterally. Developmental anomalies once formed would persist postnatally. ${ }^{8,9}$ The knowledge of course and relations of nerves in relation to coracobrachialis are important, as any nerves entering this muscle is susceptible to injury during any anterior shoulder surgery that involves mobilization or retraction of muscle attached to coracoids process, like coracoid osteotomy, coracoid process transfer, transection, and rerouting of the muscle attached to coracoid process. ${ }^{3}$ Unaccustomed positioning 
of the upper extremity in abduction, external rotation, or extension during general anesthesia can stretch coracobrachialis, thus putting at risk any nerve piercing the muscle and may cause entrapment neuropathy. Injury to musculocutaneous nerve at coracobrachialis level secondary to heavy physical exercises or athletic training is a well-known phenomenon. ${ }^{4,10}$ Same mechanisms may lead to compression of LRMN with resultant weakness, atrophy, or sensory loss in median nerve territory of distribution. Simultaneous involvement of median and musculocutaneous nerves at coracobrachialis level is not known in clinical practice. ${ }^{1}$ Such variation might be the reason for involvement of both median and musculocutaneous nerves in entrapment neuropathy at the level of coracobrachialis muscle. Lo et $\mathrm{al}^{11}$ studied the distance between lateral cord and coracoid process and discussed its clinical relevance in arthroscopic surgery. The mean distance of lateral cord to coracoid process was $28.5 \mathrm{~mm}$. Pan et $\mathrm{al}^{12}$ in 2008 observed the reduction of this distance with increase in arm abduction. In present study, the lateral cord was much longer on right $(60.7 \mathrm{~mm})$ than on left side $(10.6 \mathrm{~mm})$ and because of smaller length it terminated above clavicle on the left side. In our specimen, median nerve formation occurred at distal level than the usual. In mid-humeral approach of regional nerve block for hand surgery, such variation may result in inadequate analgesia. $^{13}$

In most of the cases of Kerr's study, only a single branch to coracobrachialis was observed, however in other cases, branches varied from two to four; at least one branch originated from musculocutaneous nerve and other branches from some other part of brachial plexus. ${ }^{14}$ In another study, most commonly two branches were found; all took origin from musculocutaneous nerve. ${ }^{15}$ In the present study, three branches were seen bilaterally and the origin of branches differed on two sides. One on the right side and two on the left side arose from musculocutaneous nerve; remaining branches arose from the lateral cord on the left side and the medial cord on the right side. Origin from the medial cord was an unusual presentation which has not been reported in the literature. In our study, 1st branch entered the coracobrachialis muscle 32 and $26 \mathrm{~mm}$ distal to coracoid process on right and left sides respectively, which was much less than the standard safe zone of 5 to $8 \mathrm{~cm} .^{3}$ This finding has clinical relevance as high entry of branches into coracobrachialis may make it vulnerable to injury. Median nerve is most commonly compressed at forearm or wrist level. ${ }^{16}$ If its compression is suspected in arm, possibility of such variation of lateral root piercing the coracobrachialis muscle should be kept in mind.

\section{REFERENCES}

1. William PL, Bannister LH, Berry MM, Collins P, Dyson M, Dussek JE, Ferguson MWJ. Nervous system. In: Grays anatomy. 38th ed. New York (NY): Churchill Livingstone; 1995. p. 1266-1271.

2. Caspi I, Ezra E, Nerubay J, Horoszovski H. Musculocutaneous nerve injury after coracoid process transfer for clavicle instability. Acta Orthop Scand 1987 Jun;58(3):294-295.

3. Flatow EL, Bigliani LU, April EW. An anatomic study of the musculocutaneous nerve and its relationship to the coracoid process. Clin Orthop Relat Res 1989 Jul;244:166-171.

4. Pecina M, Bojanić I. Musculocutaneous nerve entrapment in the upper arm. Int Orthop 1993;17(4):232-234.

5. Abhaya A, Khanna J, Prakash R. Variations of the lateral cord of brachial plexus piercing coracobrachialis muscle. J Anat Soc India 2003;52(2):168-170.

6. Butz JJ, Shiwlochan DJ, Brown KC, Prasad AM, Murlimanju BV, Viswanath S. Bilateral variations of brachial plexus involving the median nerve and lateral cord: an anatomical case study with clinical implications. Australas Med J 2014 May 31;7(5):227-231.

7. Sannes HD, Rey TA, Harris W. Development of nervous system. In: Axon growth and guidance. New York (NY): Academic Press; 2000. p. 189-197.

8. Arey LB. Developmental anatomy: a text book of embryology. In: The muscular system. 7th ed. Philadelphia (PA): WB Saunders Co; 1966. p. 501-504.

9. Brown MC, Hopkins WG, Keynes RJ. Essentials of neural development in axons guidance and target recognition. Cambridge: Cambridge University Press; 1991. p. 46-66.

10. Hsu JC, Paletta GA, Gambardella RP, Jobe FW. Musculocutaneous nerve injury in major league baseball pitchers: a report of 2 cases. Am J Sports Med 2007 Jun;35(6):1003-1006.

11. Lo IK, Burkhart SS, Parten PM. Surgery about the coracoid neurovascular structures at risk. Arthroscopy 2004 Jul;20(6):591-595.

12. Pan WJ, Teo YS, Chang HC, Chang KC, Karim SA. The relationship of the lateral cord of the brachial plexus to the coracoid process during arthroscopic coracoids surgery: a dynamic cadaveric study. Am J Sports Med 2008 Oct;36(10):1998-2001.

13. Pianezza A, Salces y Nedeo A, Chaynes P, Bickler PE, Minville V. The emergence level of the musculocutaneous nerve from the brachial plexus: implications for infraclavicular nerve blocks. Anesth Analg 2012 May;114(5):1131-1133.

14. Kerr AT. The brachial plexus of nerves in man, the variation on its formation and branches. Am J Anat 1918;23:285-295.

15. Oztruk A, Bayraktar B, Taskara N, Kale AC, Kutlu C, Cecen A. Morphometric study of the nerves entering into the coracobrachialis muscle. Surg Radiol Anat 2005 Nov;27(4):308-311.

16. Bednar MS, Light TR. Compressive neuropathy. In: Skinner HB, editor. Current diagnosis and treatment in orthopaedics. 3rd ed. New York (NY): McGraw-Hill Professional; 2003. p. 550-556. 